\title{
INFLUÊNCIA DO ESTÁDIO DE MATURAÇÃO E DA EMBALAGEM DE POLIETILENO NA FRIGOCONSERVAÇÃO DE AMEIXA ${ }^{1}$
}

\author{
RICARDO ALFREDO KLUGE ${ }^{2}$, ALDONIR BARREIRA BILHALVA ${ }^{3}$ e RUFINO FERNANDO FLORES CANTILLANO ${ }^{4}$
}

RESUMO - Um experimento visando verificar a influência do estádio de maturação e da embalagem de polietileno, durante o armazenamento de ameixa (Prunus salicina Lindl.) cultivar Amarelinha, foi realizado na Embrapa - Centro de Pesquisa Agropecuária de Clima Temperado (CPACT), em Pelotas, RS. Foram utilizadas frutas em três estádios de maturação: verde, semimaduro e maduro, embaladas ou não em sacos de polietileno. O armazenamento refrigerado realizou-se a $0^{\circ} \mathrm{C}$ e $90-95 \% \mathrm{UR}$, por 14,28 e 42 dias, seguido da comercialização simulada por três dias a $25-26^{\circ} \mathrm{C}$. As frutas semimaduras foram as que perderam menos peso ao longo da frigoconservação e comercialização simulada. A embalagem de polietileno reduziu as perdas de peso para menos de $1 \%$ ao longo do armazenamento. As frutas não embaladas perderam até $7 \%$ em peso, apresentando sintomas de murchamento a partir dos 28 dias, principalmente as do estádio maduro. A firmeza de polpa e a acidez total titulável decresceram ao longo do experimento nos três estádios de maturação, e a perda elevada de acidez resultou em sobrematuração das frutas, principalmente aos 42 dias de armazenamento. Não ocorreu desintegração interna nas frutas e a incidência de podridões aumentou aos 42 dias. Conclui-se que o armazenamento refrigerado deve ser feito até os 28 dias.

Termos para indexação: Prunus salicina, armazenamento refrigerado.

\section{INFLUENCE OF RIPENING STAGE AND POLYETHYLENE PACKAGING ON COLD STORAGE OF PLUM}

\begin{abstract}
Aiming to verify the influence of ripening stage and polyethylene packaging on cold storage of plum (Prunus salicina Lindl.) Amarelinha cultivar, an experiment was conducted in Embrapa - Centro de Pesquisa Agropecuária de Clima Temperado (CPACT), Pelotas, RS State Brazil. Three ripening stage fruits were used: green, semi-ripe and ripe, packed or not with polyethylene bags. Fruits were cold stored at $0^{\circ} \mathrm{C}$ and $90-95 \%$ RH during 14, 28 and 42 days, followed by three days of market simulation at ambient temperature $\left(25-26^{\circ} \mathrm{C}\right)$. Polyethylene bags reduced weight loss for less than $1 \%$ during cold storage while unwrapped fruits lost up to $7 \%$ of weight, showing wilt symptoms after 28 days, mainly for ripe stage. The firmness and titratable acidity decreased along the experiment for the three ripening stage. The high acidity decrease caused fruit overripening mainly for 42 days of cold storage. There was no fruit internal breakdown and decay incidence increased at 42 days. Cold storage is recommended for this cultivar until 28 days.
\end{abstract}

Index terms: Prunus salicina, fruit storage.

\footnotetext{
${ }^{1}$ Aceito para publicação em 13 de abril de 1998.

${ }^{2}$ Eng. Agr., M.Sc., doutorando do Curso de Pós-Graduação em Fitotecnia da ESALQ/USP, Dep. de Horticultura, ESALQ/USP, Caixa Postal 9, CEP 13418-900 Piracicaba, SP. E-mail: rakluge@carpa.ciagri.usp.br

${ }^{3}$ Eng. Agr., Ph.D, Prof. Titular, Dep. de Ciência e Tecnologia Agroindustrial, FAEM/UFPEL, Caixa Postal 354, CEP 96010-900 Pelotas, RS.

${ }^{4}$ Eng. Agr., M.Sc., Embrapa-Centro de Pesquisa Agropecuária de Clima Temperado (CPACT), Caixa Postal 403, CEP 96001-970 Pelotas, RS.
}

\section{INTRODUÇÃO}

A cultura da ameixeira tem sido vista como uma boa alternativa para os produtores de frutas frescas. Dentre as espécies de ameixeira existentes, a mais cultivada no Brasil é a Prunus salicina Lindl., ou ameixeira japonesa. Na região sul do Rio Grande do Sul diversas cultivares possuem potencial para a exploração comercial, entre elas a cultivar Amarelinha, que caracteriza-se por produzir frutos de tamanho 
médio a grande, com epiderme e polpa amarelas e boa qualidade. $\mathrm{O}$ amadurecimento das ameixas, na região de Pelotas, ocorre a partir da $2^{2}$ quinzena de janeiro (Nakasu \& Castro, 1990).

No Brasil existem poucas informações de pesquisas referentes ao armazenamento refrigerado de ameixas dessa e de outras cultivares.

O armazenamento sob baixas temperaturas é dos métodos mais utilizados para a manutenção da qualidade das frutas após a colheita. Além disso, a frigoconservação tem a finalidade de prolongar o período de comercialização (Chitarra \& Chitarra, 1990).

As ameixas, em geral, não são adaptadas a longos períodos de armazenamento refrigerado, devido a problemas de desidratação, distúrbios fisiológicos e ocorrência de fungos de armazenamento (Hardenburg et al., 1986; Cantillano, 1987).

As técnicas que vêm sendo pesquisadas para a solução de tais problemas incluem a embalagem das frutas em materiais de plástico, como complemento na refrigeração, visto que esta, por si só, muitas vezes é insuficiente para manter a qualidade das frutas. O uso do plástico como embalagem tem como função diminuir os ritmos metabólicos que levam a fruta à senescência, por meio da modificação do ar ambiental ao redor dela, com diminuição dos níveis de $\mathrm{O}_{2}$ e aumento nos níveis de $\mathrm{CO}_{2}$ (Hardenburg, 1971; Smith et al., 1987). Alguns materiais de plástico utilizados na embalagem de ameixas são o PVC (cloreto de polivinila) e o polietileno de baixa densidade, que têm resultado em diminuição das perdas de peso do produto, conforme trabalhos realizados por Donoso \& Galdames (1973); Filgueiras (1986) e Kluge \& Jorge (1992).

Os distúrbios fisiológicos que ocorrem em ameixas aparecem principalmente no período pós-colheita, sendo dos mais significativos os relacionados com o escurecimento da polpa, comumente conhecidos como desintegração interna "Internal Breakdown". Tal alteração caracteriza-se pela perda da organização celular decorrente da instabilidade das membranas e paredes celulares, tornando escurecidos e impalatáveis os tecidos da polpa da fruta (Eksteen, 1982). A susceptibilidade varietal a este distúrbio é um dos determinantes do potencial de conservação de ameixas (Gatti \& Escudero, 1985).
O estádio de maturação da fruta, no momento da colheita, é outro determinante da longevidade de ameixas no período pós-colheita (Chitarra \& Chitarra, 1990). A colheita demasiadamente precoce resulta em perda de peso e tamanho, além de predispor as frutas à desidratação, amadurecimento anormal e distúrbios fisiológicos durante o armazenamento refrigerado (Reszczynsky, 1977; Muñoz, 1982). Por outro lado, a colheita demasiadamente tarde encurta o período de armazenamento da fruta por aproximá-la da senescência, além de favorecer a desidratação, o amaciamento demasiado, os distúrbios fisiológicos e o aparecimento de sabores estranhos ou sobrematuração (Torrellardona, 1983).

O presente trabalho teve como objetivos verificar a capacidade de armazenamento refrigerado de ameixas da cultivar Amarelinha, em diferentes estádios de maturação, e avaliar os efeitos da embalagem de polietileno durante o armazenamento.

\section{MATERIAL E MÉTODOS}

O trabalho foi realizado na Embrapa - Centro de Pesquisa Agropecuária de Clima Temperado (CPACT), em Pelotas, RS. Foram utilizadas ameixas da cultivar Amarelinha, colhidas na safra 1992/93 e provenientes de um pomar de seis anos localizado na referida unidade.

As frutas foram selecionadas conforme estádios de maturação diferentes, identificados pela cor da casca: estádio verde (frutas de coloração verde-clara); estádio semimaduro (frutas de coloração amarela); e estádio maduro (frutas de coloração amarela com sutura avermelhada). No total, foram colhidas 200 frutas para cada estádio de maturação, sendo descartadas aquelas com danos por insetos, doenças ou pássaros ou com tamanho fora do padrão (demasiadamente pequenas ou grandes).

Após a seleção, as frutas foram submetidas a um tratamento por imersão durante 1 minuto, em uma solução fungicida contendo Benomyl (Benlate a $0,6 \%$ do produto comercial), em seguida separadas em repetições de 15 frutas e colocadas em redes de plástico, amarradas e etiquetadas. A metade das frutas selecionadas foi embalada em sacos de polietileno da baixa densidade, com espessura de $20 \mu$ e 12 perfurações de $7 \mathrm{~mm}$, grampeados na parte superior. $\mathrm{O}$ acondicionamento final das frutas se deu em caixas de madeira.

O armazenamento refrigerado ocorreu em câmara frigorífica de propriedade da Companhia Estadual de Silos 
e Armazéns (CESA), de Pelotas. A temperatura e a umidade relativa foram reguladas para $0 \pm 0,5^{\circ} \mathrm{C}$ e $90-95 \%$, respectivamente, e monitoradas com termohigrógrafo THG-1.

As frutas foram submetidas a 14,28 e 42 dias de armazenamento refrigerado, e em seguida colocadas em temperatura ambiente por três dias $\left(25-26^{\circ} \mathrm{C}\right)$, simulando uma comercialização.

Os parâmetros avaliados foram: a) peso médio: realizado na colheita, quando foram pesadas quatro repetições de 15 frutas; b) diâmetro médio: realizado na colheita, com paquímetro, medindo-se o diâmetro transversal e o longitudinal; c) cor: utilizando tabelas de cores do Código Universal de Cores (Séguy, 19--); d) perda de peso: avaliada imediatamente após cada período de armazenamento e após a comercialização simulada, cujos resultados foram expressos em porcentagem; e) firmeza de polpa: foi medida com o auxílio de um penetrômetro com ponteira $5 / 16$ polegadas de diâmetro, fazendo-se duas leituras em lados opostos da secção equatorial das frutas. Os dados foram expressos em libras $/ \mathrm{pol}^{2}$; f) teor de sólidos solúveis totais (SST): foi determinado por meio de refratometria, expressando em ${ }^{\circ}$ Brix, com correção da temperatura para $20^{\circ} \mathrm{C}$; g) acidez total titulável (ATT): determinada por titulometria, com $\mathrm{NaOH} 0,1 \mathrm{~N}$ até $\mathrm{pH} 8,1$ e expressa em porcentagem de ácido málico; h) relação SST/ATT: determinada pelo quociente entre os constituintes SST e ATT; i) incidência de podridões: foram consideradas afetadas aquelas com sintomas visíveis de deterioração fúngica. Os resultados foram expressos em porcentagem de frutas afetadas; j) incidência de desintegração interna: foi avaliada mediante análise visual, considerando como frutas afetadas aquelas com a polpa escurecida e os resultados expressos em porcentagem.

O delineamento experimental utilizado foi o inteiramente casualizado e em cada estádio de maturação foi observado um esquema fatorial $2 \times 4$, com quatro repetições de 15 frutas. Os fatores estudados foram: sistema de embalagem (sem e com sacos de polietileno) e tempo de armazenamento, em quatro períodos (zero, representando a colheita, 14, 28 e 42 dias).

Os dados coletados durante o armazenamento refrigerado foram submetidos à análise de variância. Para o estudo do fator tempo de armazenamento foi utilizada a regressão polinomial. Para as variáveis perda de peso e podridões foi incluído o fator estádio de maturação.

$\mathrm{Na}$ avaliação da colheita foram utilizadas quatro repetições de 15 frutas, de diferentes estádios de maturação, sendo os resultados submetidos à comparação múltipla de média pelo teste de Duncan a 5\% de probabilidade.

\section{RESULTADOS E DISCUSSÃO}

Na Tabela 1 são apresentados os resultados das características físicas e químicas das frutas no momento da colheita.

A caracterização dos três estádios de maturação pela cor, mesmo sendo um índice subjetivo, mostrase confiável para a determinação do ponto de colheita das frutas dessa cultivar, haja vista as diferenças encontradas principalmente quanto à firmeza de polpa. A firmeza das frutas é um dos parâmetros de qualidade mais importantes. Com o avanço do processo de maturação, as frutas vão ficando mais macias devido à hidrólise das pectinas que compõem a parede celular (Braverman, 1980). Tal fato vem explicar os resultados encontrados no presente trabalho, uma vez que as frutas em estado mais adiantado de maturação (estádio maduro) foram as que apresentaram menor firmeza de polpa (Tabela 1). A determinação da firmeza de polpa, mesmo sendo um método destrutivo, é um parâmetro que pode ser utilizado, em conjunto com a cor, para identificar o ponto de colheita.

As frutas do estádio verde alcançaram coloração amarela, semelhante às do estádio semimaduro, após os 14 dias de armazenamento. Nas frutas dos estádios semimaduro e maduro ocorreram poucas variações de coloração ao longo do experimento.

As perdas de peso das frutas aumentaram durante o armazenamento refrigerado. As frutas do estádio semimaduro foram as que perderam menos em peso, independentemente do uso do saco de polietileno (Figs. 1a e 1b). Tal comportamento pode estar relacionado com as taxas de transpiração das frutas, que, normalmente, segundo Torrellardona (1983), é maior em frutas colhidas verdes ou demasiadamente maduras, se comparadas com frutas colhidas no estádio ótimo de maturação.

O uso da embalagem de polietileno contribuiu significativamente para a redução nas perdas de peso, ficando, em todos os períodos e estádios de maturação, abaixo de 1\% (Fig. 2), concordando com os resultados encontrados por Kluge \& Jorge (1992). $\mathrm{O}$ efeito dessa embalagem se deve à manutenção de uma alta umidade relativa ao redor da fruta, com valor próximo à umidade relativa do seu interior. Isso impediu um aumento no déficit de pressão de vapor 
e, por conseqüência, diminuiu a perda de água pelas frutas mediante processo de transpiração, concordando com Hardenburg et al. (1986) e Gorris \& Peppelenbos (1992).

Aos 28 dias do armazenamento, as frutas do estádio maduro que não foram embaladas com polietileno começaram a apresentar sintomas de murchamento. Aos 42 dias, o murchamento das frutas não embaladas foi generalizado nos três estádios de maturação. Os sintomas apareceram principalmente na região próxima ao pedúnculo. Conforme Crisosto (1994), perdas de peso entre 5 a $8 \%$ em frutas de caroço podem levá-las ao murchamento. Pelos resultados do presente experimento, parece que essa cultivar não suporta perdas de peso igual ou maior aos referidos valores. As frutas embaladas com polietileno não apresentaram sintomas de murchamento ao longo do período de armazenamento refrigerado.

Durante a comercialização simulada, as perdas de peso foram, em média, $2,22 \%$ nas frutas do estádio verde, $1,87 \%$ nas do estádio semimaduro e $2,35 \%$ no estádio maduro.

Quanto à firmeza de polpa, houve diminuição acentuada ao longo do armazenamento refrigerado nos três estádios de maturação (Fig. 3). Ao final dos 42 dias de armazenamento, as frutas apresentavam valores de firmeza entre 4,5 e 5 libras/pol ${ }^{2}$ no estádio verde e próximos a 4 libras/pol ${ }^{2}$ nos estádios semimaduro e maduro. A elevada perda de firmeza das frutas dessa cultivar durante o armazenamento também foi verificada por Kluge \& Jorge (1992).

Não houve variação significativa no teor de SST nos estádios verde e semimaduro ao longo do armazenamento refrigerado, cujos valores oscilaram entre 12,52 e $13,36^{\circ}$ Brix no estádio verde e entre 13,25 e $13,63^{\circ}$ Brix no estádio semimaduro.

Já as frutas do estádio maduro, que não foram embaladas com o polietileno, aumentaram em pouco mais de $1^{\circ}$ Brix o teor de SST da colheita até os 42 dias de armazenamento (de $14,41^{\circ}$ Brix para $15,61^{\circ}$ Brix), podendo este fato estar relacionado com a maior perda de peso verificada nessas frutas na fase de armazenamento, conforme observa-se na Fig. 1. A perda de peso provavelmente concentrou os açúcares nos tecidos, concordando com os resultados encontrados por Francisconi et al. (1991), que observaram aumentos no teor de SST nessa cultivar em função da perda de peso das frutas durante o armazenamento.

A acidez total titulável diminuiu ao longo do armazenamento, em todos os estádios de maturação (Fig. 4), alcançando valores muito próximos ao final do experimento. As frutas que perderam mais ácidos em proporcionalidade foram as do estádio verde, uma vez que na colheita eram as mais ácidas e ao final dos 42 dias de armazenamento refrigerado foram as menos ácidas. Esses resultados são similares aos encontrados por Kluge \& Jorge (1992), que verificaram perdas de até $50 \%$ de ácidos ao longo de 20 dias de armazenamento a $2^{\circ} \mathrm{C}$, com essa cultivar.

A relação SST/ATT aumentou ao longo do armazenamento (Fig. 5). Isso se deve em maior parte à diminuição da ATT sofrida pelas frutas durante o experimento. Nos estádios verde e maduro, a relação chegou próximo a 40 ao final de 42 dias de armazenamento, enquanto no estádio semimaduro

TABELA 1. Características físicas e químicas de ameixas (Prunus salicina Lindl.) cultivar Amarelinha colhidas em três estádios de maturação ${ }^{1}$.

\begin{tabular}{lcccc}
\hline \multirow{2}{*}{ Característica } & \multicolumn{3}{c}{ Estádios de maturação } & \multirow{2}{*}{ C.V. } \\
\cline { 2 - 4 } & Verde & Semimaduro & Maduro & $(\%)$ \\
\hline Peso médio (g) & $71,08 \mathrm{a}$ & $69,70 \mathrm{a}$ & $61,86 \mathrm{a}$ & 7,93 \\
Diâmetro longitudinal (mm) & $51,40 \mathrm{a}$ & $48,28 \mathrm{a}$ & $46,51 \mathrm{a}$ & 11,76 \\
Diâmetro transversal (mm) & $51,24 \mathrm{a}$ & $50,34 \mathrm{a}$ & $49,62 \mathrm{a}$ & 7,33 \\
Firmeza de polpa (libras/pol $\left.{ }^{2}\right)$ & $14,09 \mathrm{a}$ & $10,69 \mathrm{~b}$ & $8,54 \mathrm{c}$ & 3,47 \\
Sólidos solúveis totais ( $\left.{ }^{(} \mathrm{Brix}\right)$ & $13,36 \mathrm{a}$ & $13,63 \mathrm{ab}$ & $14,41 \mathrm{~b}$ & 4,39 \\
Acidez total titulável $(\%)$ & $0,85 \mathrm{a}$ & $0,64 \mathrm{~b}$ & $0,69 \mathrm{~b}$ & 7,43 \\
Relação SST/ATT & $15,71 \mathrm{a}$ & $21,30 \mathrm{~b}$ & $21,19 \mathrm{~b}$ & 7,67 \\
\hline
\end{tabular}

${ }^{1}$ Médias seguidas de mesma letra na linha, não diferem entre si pelo teste de Duncan a $5 \%$ de probabilidade. 
ficou um pouco acima de 30. A elevação desse parâmetro originou alguns sintomas de sobrematuração a partir dos 28 dias de armazenamento. Aos 42 dias verificou-se que a sobrematuração foi geral, independentemente do estádio de maturação, ou seja, apesar de as frutas apresentarem boa aparência externa, encontravam-se demasiadamente doces e com pouca acidez.
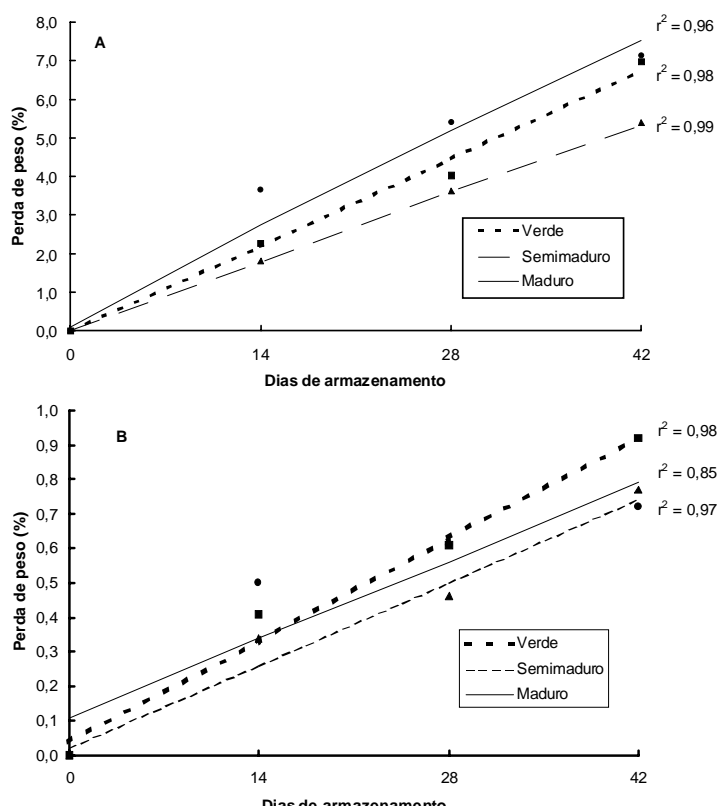

FIG. 1. Efeito do estádio de maturação na perda de peso em ameixas (Prunus salicina Lindl.), cultivar Amarelinha, armazenadas a $0^{\circ} \mathrm{C}$ e 90-95\% UR. (A = sem polietileno; $B=$ com polietileno).

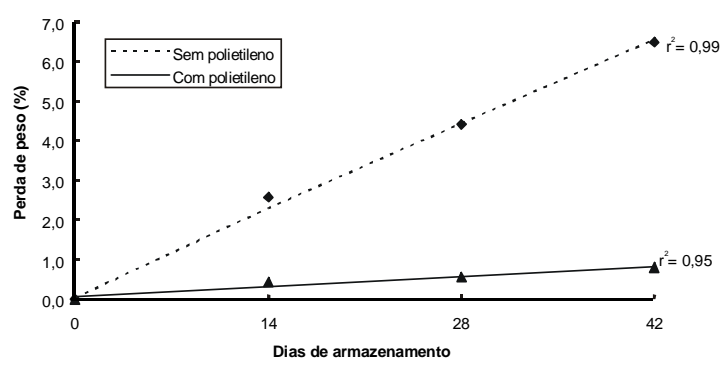

FIG. 2. Efeito da embalagem de polietileno na perda de peso em ameixas (Prunus salicina Lindl.) cultivar Amarelinha, armazenadas a $0^{\circ} \mathrm{C}$ e 90-95\% UR.
As frutas da cultivar estudada não apresentaram sintoma de desintegração interna de polpa, ao longo do armazenamento e da comercialização, indicando ser de baixa susceptibilidade a tal distúrbio, pelo menos até 42 dias de armazenamento sob as condições impostas no presente experimento.

Os maiores índices de frutas podres ocorreram aos 42 dias de armazenamento (Tabela 2). Não houve efeito do uso do polietileno na incidência de podridões nas frutas. Os fungos que apareceram com maior freqüência foram Monillia sp., Rhizopus sp. e Penicillium sp.

As frutas do estádio semimaduro, caracterizadas por apresentarem-se completamente amarelas e com

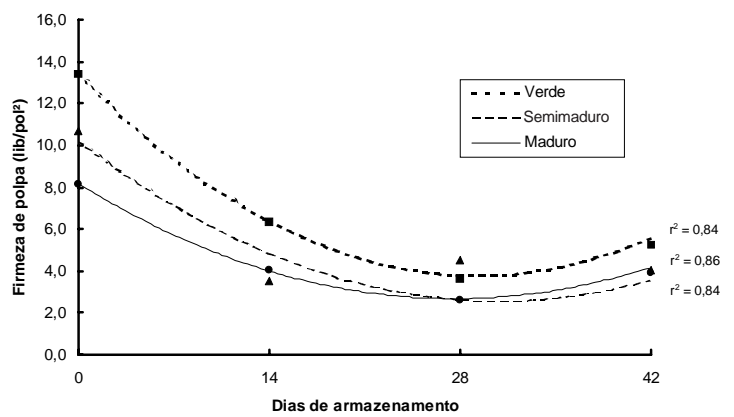

FIG.3. Firmeza de polpa em ameixas (Prunus salicina Lindl.) cultivar Amarelinha, colhidas em três estádios de maturação e armazenadas a $0^{\circ} \mathrm{C}$ e $90-95 \%$ UR.

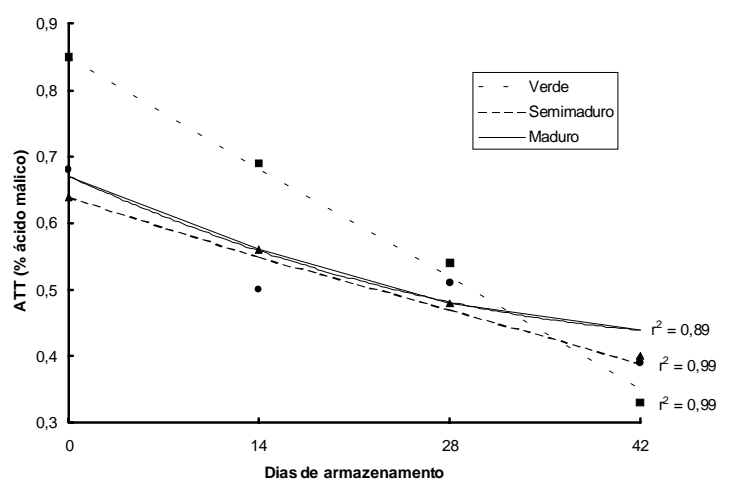

FIG.4. Acidez total titulável (ATT) em ameixas (Prunus salicina Lindl.) cultivar Amarelinha, colhidas em três estádios de maturação e armazenadas a $0^{\circ} \mathrm{C}$ e $90-95 \%$ UR.

Pesq. agropec. bras., Brasília, v.34, n.3, p.323-329, mar. 1999 


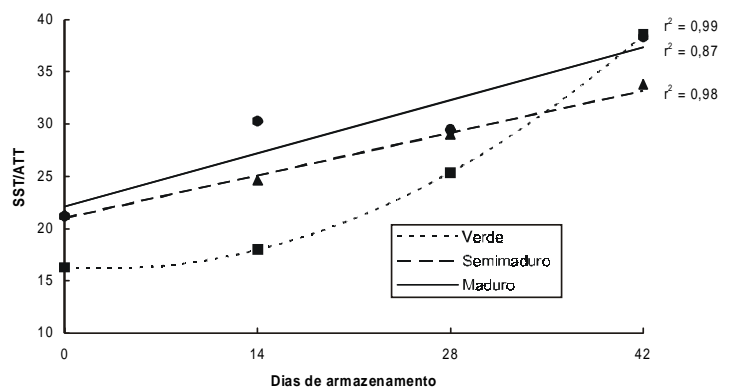

FIG. 5. Relação sólidos solúveis totais/acidez total titulável (SST/ATT) em ameixas (Prunus salicina Lindl.) cultivar Amarelinha, colhidas em três estádios de maturação e armazenadas a $0^{\circ} \mathrm{C}$ e $\mathbf{9 0 - 9 5 \%} \mathrm{UR}$.

TABELA 2. Incidência de podridão (\%) em ameixas (Prunus salicina Lindl.) cultivar Amarelinha colhidas em três estádios de maturação e armazenadas a $0^{\circ} \mathrm{C}$ e 90-95\% UR, sem e com embalagem de polietileno.

\begin{tabular}{lcccc}
\hline \multirow{2}{*}{ Estádio } & \multirow{2}{*}{$\begin{array}{c}\text { Embalagem } \\
\text { de polietileno }\end{array}$} & \multicolumn{3}{c}{ Dias de armazenamento } \\
\cline { 3 - 5 } & Sem & - & - & 28,33 \\
\hline \multirow{2}{*}{ Verde } & Com & - & 1,66 & 30,00 \\
& Semimaduro & - & 3,33 & 21,66 \\
& Com & - & 11,66 & 23,33 \\
Maduro & Sem & 1,67 & 3,33 & 13,33 \\
& Com & 8,33 & 10,00 & 11,68 \\
\hline
\end{tabular}

firmeza de polpa entre 10 e 11 libras $/ \mathrm{pol}^{2}$, no momento da colheita, foram as que melhor se comportaram durante $\mathrm{o}$ armazenamento refrigerado, por revelarem menores perdas de peso ao longo do experimento. Quanto ao período máximo de conservação, é aconselhável não armazená-la por mais de 28 dias, pois nesse período começam a aparecer sintomas de sobrematuração, com perdas na qualidade.

O uso do polietileno, mesmo não tendo atuado sobre as principais características de qualidade das frutas, foi importante na redução do déficit de pressão de vapor entre a fruta e o ambiente, diminuindo desta maneira as perdas de umidade da fruta e evitando o murchamento.

A cultivar Amarelinha é promissora para armazenamentos mais longos, por resistir bem à desintegração interna de polpa. Entretanto, devem ser buscadas soluções que previnam elevadas perdas de acidez durante o armazenamento e a comercialização, evitando assim os sintomas de sobrematuração com o prolongamento da frigoconservação.

\section{CONCLUSÕES}

1. Ameixas da cv. Amarelinha podem ser conservadas a $0^{\circ} \mathrm{C}$ e $90-95 \%$ UR por 28 dias.

2. As frutas colhidas no estádio semimaduro (coloração amarela e firmeza de polpa $=10-11$ libras $/ \mathrm{pol}^{2}$ ) se conservam melhor do que frutas de estádios menos ou mais avançados.

3. O uso de embalagem de polietileno durante o armazenamento refrigerado de ameixas cv. Amarelinha reduz as perdas de peso das frutas.

\section{AGRADECIMENTOS}

Ao pesquisador Luis Antônio Suíta de Castro e aos funcionários Núbia Marilin Lettnin Ferri, Alessandra Tavares Medeiros e Valter Lopes Abrantes, do CPACT, pelo auxílio prestado na condução do trabalho.

\section{REFERÊNCIAS}

BRAVERMAN, J.B.S. Introducción a la bioquímica de los alimentos. México: Editorial El Manual Moderno, 1980. 358p.

CANTILLANO, R.F. Fisiologia e manejo de pós-colheita de ameixas. Pelotas: Embrapa-CNPFT, 1987. $10 \mathrm{p}$.

CHITARRA, M.I.F.; CHITARRA, A.B. Pós-colheita de frutos e hortaliças: fisiologia e manuseio. Lavras: ESAL/FAEPE, 1990. 320p.

CRISOSTO, C.H. Factores que afectan la calidad de la fruta y su deterioro en postcosecha. In: CURSO INTERNACIONAL DE FRUTALES DE CAROZO, 1994, General Roca, Rio Negro. Anais... General Roca, Rio Negro: [s.n.], 1994. cap.7.1, p.1-10. 
DONOSO, G.C.; GALDAMES, J.O. Efectos del grado de madurez, periodo de almacenaje y sistemas de embalaje sobre la calidad de ciruelas de exportación. Santiago de Chile: Corfo-Enafri, 1973. $150 \mathrm{p}$.

EKSTEEN, G.J. Internal breakdown of plums. The Deciduous Fruit Grower, Stellenbosch, v.32, n.9, p.359-361, 1982.

FILGUEIRAS, H.A.C. Conservação pós-colheita de ameixas (Prunus sp. cv. Roxa de Delfim Moreira) em quatro estádio de maturação. Lavras: ESAL, 1986. 131p. Tese de Mestrado.

FRANCISCONI, A.H.D.; MARODIN, G.A.B.; BENDER, R.J. Efeito de fungicidas no controle póscolheita da podridão parda e características físicoquímicas de ameixas (Prunus salicina Lindl.) "Amarelinha" em dois períodos de armazenamento. Revista Brasileira de Fruticultura, Cruz das Almas, v.13, n.4, p.69-74, 1991.

GATTI, R.; ESCUDERO, P. Pardeamiento interno en frutales de carozo. Revista Fruticola, Curicó, v.6, n.2, p.45-48, 1985.

GORRIS, L.G.M.; PEPPELENBOS, H.W. Modified atmosphere and vacuum packaging to extend the shelf life of respiring food products. HortTechnology, Alexandria, v.2, n.3, p.303-309, 1992.

HARDENBURG, R.E. Effect of in package environment on keeping quality of fruits and vegetables. HortScience, Alexandria, v.8, n.3, p.198-201, 1971.
HARDENBURG, R.E.; WATADA, A.E.; WANG, C.Y. The commercial storage of fruits, vegetables, and florist, and nursery stocks. Washington, USDA, 1986. $130 \mathrm{p}$.

KLUGE, R.A.; JORGE, R.O. Efeito da embalagem de polietileno na frigoconservação de ameixas "Amarelinha”. Revista Brasileira de Fruticultura, Cruz das Almas, v.14, n.3, p.21-25, 1992.

MUÑOZ, A.R.M. Pudriciones en fruta de exportación y mercado interno. Revista Frutícola, Curicó, v.3, n.3, p.83-86, 1982.

NAKASU, B.H.; CASTRO, L.A.S. Indicação de cultivares de ameixeira para o sul do Brasil. Hortisul, Pelotas, v.1, n.2, p.24-28, 1990.

RESZCZYNSKY, A. Estudio de madurez de exportación en ciruelas El Dorado. In: SIMPÓSIO SOBRE MANEJO, CALIDAD Y FISIOLOGIA DE POSTCOSECHA DE FRUTAS, 2., 1977, San Felipe. Anais... San Felipe: [s.n.], 1977. p.120-126. (Publicaciones miscelaneas, n.12).

SÉGUY, E. XXX Code Universel des couleurs. Paris: Paul Lechevalier, [19--]. 48p.

SMITH, S.; GEESON, J.; STOW, J. Production of modified atmosphere in deciduous fruit by the use of films and coating. HortScience, Alexandria, v.22, n.5, p.772-776, 1987.

TORRELLARDONA, S.D. Frigoconservación de la fruta. Barcelona: AEDOS, 1983.369p. 